\title{
Porphyrin-Based Organoplatinum(II) Metallacycles With Enhanced Photooxidization Reactivity
}

\author{
Lintao Wu ${ }^{1}$, Chun Han ${ }^{1}$, Zhijun Wang ${ }^{1}$, Xi Wu ${ }^{1}$, Feng Su ${ }^{1}$, Mengyao $\mathrm{Li}^{1}$, Qingyang Zhang ${ }^{2 \star}$ \\ and Xiaobi Jing ${ }^{3 *}$
}

${ }^{1}$ Department of Chemistry, Changzhi University, Changzhi, China, ${ }^{2}$ State Key Laboratory of Bioactive Substances and Function of Natural Medicine, Institute of Materia Medica, Chinese Academy of Medical Sciences and Peking Union Medical College, Beijing, China, ${ }^{3}$ School of Chemistry and Chemical Engineering, Yangzhou University, Yangzhou, China

OPEN ACCESS

Edited by:

Yong Yao,

Nantong University, China

Reviewed by:

Mingliang Liu,

Chinese Academy of Medical

Sciences and Peking Union Medical

College, China

Yang Wang

Nantong University, China

*Correspondence:

Qingyang Zhang

zhangqingyang@imm.ac.cn

Xiaobi Jing

xbjing@yzu.edu.cn

Specialty section:

This article was submitted to

Supramolecular Chemistry,

a section of the journal

Frontiers in Chemistry

Received: 17 February 2020

Accepted: 18 March 2020

Published: 28 April 2020

Citation:

Wu L, Han C, Wang Z, Wu X, Su F,

Li M, Zhang $Q$ and Jing X (2020)

Porphyrin-Based Organoplatinum(II)

Metallacycles With Enhanced

Photooxidization Reactivity.

Front. Chem. 8:262.

doi: 10.3389/fchem.2020.00262
In recent years, metal coordination macrocycles have obtained great interests due to the fact that they combined the rich host-guest properties of macro-cyclic hosts and the unique optical properties of the organic ligands. In this work, we constructed two porphyrin-based organoplatinum(II) metallacycles (MC1 and MC2) through coordination-driven self-assembly. ${ }^{1} \mathrm{H}$ NMR, ${ }^{31} \mathrm{P} N \mathrm{NM}$, and HRMS technologies were used to characterize the structures of $\mathbf{M C 1}$ and $\mathbf{M C 2}$. Interestingly, MC1 and MC2 can be used as catalysts for photooxidization under light irradiation with higher efficiency compared with the porphyrin ligand only. We hope that the coordination-driven self-assembly strategy can provide an efficient method to construct photo-active materials.

Keywords: self-assembly, macrocycle, porphyrin, photooxidization, coordination

\section{INTRODUCTION}

Macrocyclic host compounds, mainly including crown ethers (Zhu et al., 2012; Liu et al., 2017), cyclodextrins (Lai et al., 2017; Li et al., 2019), calixarenes (Kim et al., 2012; Nimse and Kim, 2013), cucurbiturils (Kim et al., 2007; Barrow et al., 2015), and pillararenes (Xue et al., 2012; Ogoshi et al., 2016; Yao et al., 2017; Chen J. et al., 2019), are the foundation of the development of supramolecular chemistry (Dong et al., 2014; Sun et al., 2018; Gao L. et al., 2019; Xiao et al., 2019). During the past two decades, the syntheses, host-guest properties, and applications of macrocycles have been widely investigated (Chen Y. et al., 2019; Wu and Yang, 2019). Among various macrocycles, discrete organoplatinum(II) metallacycles, which was fabricated by a new valuable strategy called "coordination-driven self-assembly," attracted great interests from both chemists and materials scientists (Gao S. et al., 2019; Zhang et al., 2019). A remarkable advantage of the "coordination-driven self-assembly" is that two-dimensional metallacycles or three-dimensional metallacages can be easily obtained by the formation of metal-ligand bonds between metal acceptors and organic donors when combining simple building blocks (Wang et al., 2019a; Yan et al., 2019). Up to now, discrete organoplatinum(II) metallacycles have been investigated a lot and widely applied in many areas, such as fluorescent detection, homogeneous catalysis, functional materials, bioengineering, photodynamic therapy, and so on (Cai et al., 2020; Qin et al., 2019).

Porphyrin derivatives, which contain a large $\pi$-conjugated aromatic structure, are a class of famous photo-activities (Liang et al., 2011; Ou et al., 2019; Wang et al., 2019b). Porphyrins usually have very intense absorption bands in the UV-visible region. However, due to the strong $\pi-\pi$ stacking between the aromatic systems, porphyrins are easily aggregated in solvents, especially in aqueous solution (Zou et al., 2017). Commonly, porphyrins aggregate more seriously as 
the concentration increased. This aggregation phenomenon greatly decreases the efficiency of porphyrins to generate ${ }^{1} \mathrm{O}_{2}$ and therefore restrained their potentially wide applications (Zhou et al., 2019). To address the aggregation of porphyrins in water, chemistry and materials scientists usually introduce a large substituent onto the platform of the porphyrin core (Slater et al., 2015). However, these chemical synthesis and purification processes have some other disadvantages, such as being timeconsuming, tedious, and with higher costs of preparation.

Herein we designed and synthesized two new metallacycles (MC1 and MC2) with p-bipyridine-modified porphyrin (Scheme S1, Scheme 1) as organic donor and organoplatinum(II) (2 or 3 ) as the metal acceptor (Scheme 1). The weak metal-ligand bonds will prevent the $\pi-\pi$ stacking of the conjugated aromatic porphyrin units, thus improving the efficiency of generating ${ }^{1} \mathrm{O}_{2}$ under irradiation. Interestingly, compared with ligand $\mathbf{1}$ (Figure S1), the resultant metallacycle MC1 or MC2 can be used as catalyst for photo-oxidizing phenols much more efficiently.

\section{MATERIALS AND METHODS}

\section{Synthesis of Metallacycles MC1 and MC2}

Ligand 1 and organoplatinum(II) 2 (Figure 1A) and 3 (Figure 1C) were prepared according to a previous report (Grishagin et al., 2014). In a 1:1 molar ratio, bipyridylporphyrin $1(1.85 \mathrm{mg}, 3.00 \mu \mathrm{mol})$ and $60^{\circ} \mathrm{Pt}$ (II) acceptor $2(4.01 \mathrm{mg}, 3$. $00 \mu \mathrm{mol}$ ) were placed in a $2-\mathrm{ml}$ vial, followed by addition of acetone $(1 \mathrm{ml})$. After stirring overnight at $50^{\circ} \mathrm{C}$, the mixture was filtered to remove insoluble materials (Scheme S2). Then, the solvent was removed by $\mathrm{N}_{2}$ flow to about $0.2 \mathrm{ml}$, and $\mathbf{M C 1}$ was obtained by the addition of diethyl ether (5.22 mg, 89\%). MC2 was prepared by the same method (Scheme S3).

\section{MC1}

Purple solid, 89\%. ${ }^{1} \mathrm{H}$ NMR (400 MHz, $\left.\mathrm{CD}_{3} \mathrm{COCD}_{3}\right) \delta(\mathrm{ppm})$ : $10.17(\mathrm{~d}, 4 \mathrm{H}), 9.21(\mathrm{~s}, 2 \mathrm{H}), 8.92-8.90(\mathrm{~m}, 10 \mathrm{H}), 8.27-8.25$ $(\mathrm{m}, 8 \mathrm{H}), 7.89-7.85(\mathrm{~m}, 12 \mathrm{H}), 2.47-2.43(\mathrm{~m}, 24 \mathrm{H}), 1.70-1.62$ $(\mathrm{m}, 36 \mathrm{H}) .{ }^{31} \mathrm{P}\left\{{ }^{1} \mathrm{H}\right\}$ NMR (acetone, room temperature, 121.4

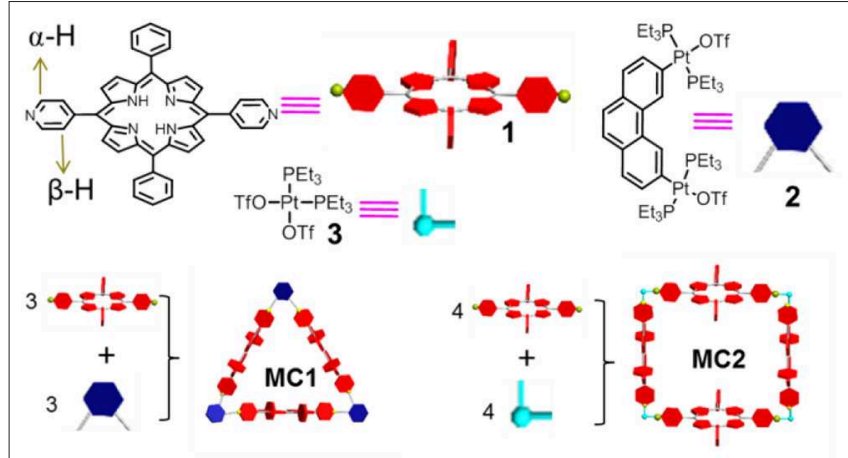

SCHEME 1 | Chemical structures and schematic diagram of p-bipyridine-modified porphyrin 1, organoplatinum(II) $\mathbf{2}$ and $\mathbf{3}$, and metallacycles $\mathbf{M C 1}$ and $\mathbf{M C 2}$.
$\mathrm{MHz}) \delta=9.53\left({ }^{195} \mathrm{Pt}\right.$ satellites, $\left.{ }^{1} J_{\mathrm{Pt}-\mathrm{P}}=2,662 \mathrm{~Hz}\right)$. HR-ESIMS: calculated for $\mathrm{C}_{203} \mathrm{H}_{288} \mathrm{~F}_{9} \mathrm{~N}_{18} \mathrm{O}_{9} \mathrm{P}_{12} \mathrm{Pt}_{6} \mathrm{~S}_{3}\left([\mathrm{M}-3 \mathrm{OTf}]^{3+}\right)$ : 1,646.78, found: $1,646.77$.

\section{MC2}

Purple solid, 87\%. ${ }^{1} \mathrm{H}$ NMR (400 $\left.\mathrm{MHz}, \mathrm{CD}_{3} \mathrm{COCD}_{3}\right) \delta(\mathrm{ppm})$ : $9.73(\mathrm{~s}, 1 \mathrm{H}), 9.61(\mathrm{~s}, 1 \mathrm{H}), 9.06(\mathrm{~s}, 2 \mathrm{H}), 8.90(\mathrm{~s}, 4 \mathrm{H}), 8.67-8.65(\mathrm{~m}$, $2 \mathrm{H}), 8.29-8.19(\mathrm{~m}, 4 \mathrm{H}), 7.86-7.74(\mathrm{~m}, 12 \mathrm{H}), 1.83-1.81(\mathrm{~m}, 24 \mathrm{H})$, $1.49-1.41(\mathrm{~m}, 36 \mathrm{H}) .{ }^{31} \mathrm{P}\left\{{ }^{1} \mathrm{H}\right\} \mathrm{NMR}$ (acetone, room temperature, 121.4 MHz) $\delta=-5.04 \mathrm{ppm}\left({ }^{195} \mathrm{Pt}\right.$ satellites, $\left.{ }^{1} J_{\mathrm{Pt}-\mathrm{P}}=3,156 \mathrm{~Hz}\right)$. HR-ESI-MS: calculated for $\mathrm{C}_{244} \mathrm{H}_{280} \mathrm{~F}_{12} \mathrm{~N}_{24} \mathrm{O}_{20} \mathrm{P}_{8} \mathrm{Pt}_{4} \mathrm{~S}_{4}([\mathrm{M}+8$ $\left.\mathrm{CH}_{3} \mathrm{COCH}_{3}-4 \mathrm{OTf}\right]^{4+}$ ): 1,316.97, found: $1,316.92$.

\section{Materials}

All reagents and solvents were commercially available in analytical grade and used as received. Further purification and drying by standard methods were employed and these were distilled prior to use when necessary. Deuterated solvents were purchased from Cambridge Isotope Laboratory (Andover, MA, USA). All evaporations of organic solvents were carried out with a rotary evaporator in conjunction with a water aspirator. Melting point measurements were taken on a hotplate microscope apparatus and are uncorrected. ${ }^{1} \mathrm{H}$ and ${ }^{13} \mathrm{C}$ NMR spectra were recorded with an Aviance III $400 \mathrm{MHz}$ or $600 \mathrm{MHz}$ liquid-state $\mathrm{NMR}$ spectrometer. ${ }^{31} \mathrm{P}\left\{{ }^{1} \mathrm{H}\right\} \mathrm{NMR}$ chemical shifts are referenced to an external unlocked sample of $85 \% \mathrm{H}_{3} \mathrm{PO}_{4}\left(\begin{array}{l}0.0\end{array}\right)$. Mass spectra were recorded on a Micromass Quattro II triple-quadrupole mass spectrometer using electrospray ionization with a MassLynx operating system. UV-vis spectra were recorded on a Hitachi F-7000 fluorescence spectrophotometer.

\section{RESULTS AND DISCUSSION}

\section{NMR Studies}

The formation of discrete organoplatinum(II) metallacycles MC1 and MC2 were characterized by multinuclear NMR $\left({ }^{31} \mathrm{P}\right.$ and $\left.{ }^{1} \mathrm{H}\right)$ analysis. The ${ }^{31} \mathrm{P}\left\{{ }^{1} \mathrm{H}\right\}$ NMR spectra of $\mathbf{M C 1}$ and MC2 showed a sharp singlet with concomitant ${ }^{195} \mathrm{Pt}$ satellites at $9.53 \mathrm{ppm}$ for MC1 and at $-5.04 \mathrm{ppm}$ for MC2 (Figures 1B,D) corresponding to a single phosphorous environment, indicating the formation of discrete and symmetric metallacycles (Wei et al., 2014).

At the same time, downshifts were observed for $\beta$-pyridyl hydrogen in ${ }^{1} \mathrm{H}$ NMR spectra. As shown in Figure 2, $\beta$-pyridyl hydrogen changed from 9.04 to 9.51 and $9.72 \mathrm{ppm}$ in $\mathrm{MC1}$ and from 9.04 to10.21 ppm in MC2. $\beta$-pyridyl hydrogen also showed a downfield chemical shift. These chemical shift changes in ${ }^{1} \mathrm{H}$ NMR spectra are similar with the previous analogous organoplatinum(II) system, indicating the formation of discrete metallacycles (Yao et al., 2018).

\section{Electrospray Ionization Time of Flight Mass Spectrometry Studies}

Electrospray ionization time of flight mass spectrometry (ESITOF-MS) provided further evidence for the stoichiometry formation of discrete metallacycles $\mathbf{M C 1}$ and $\mathbf{M C 2}$. In the mass spectrum of MC1, the peak at $\mathrm{m} / \mathrm{z}=1,646.77$ is consistent with 


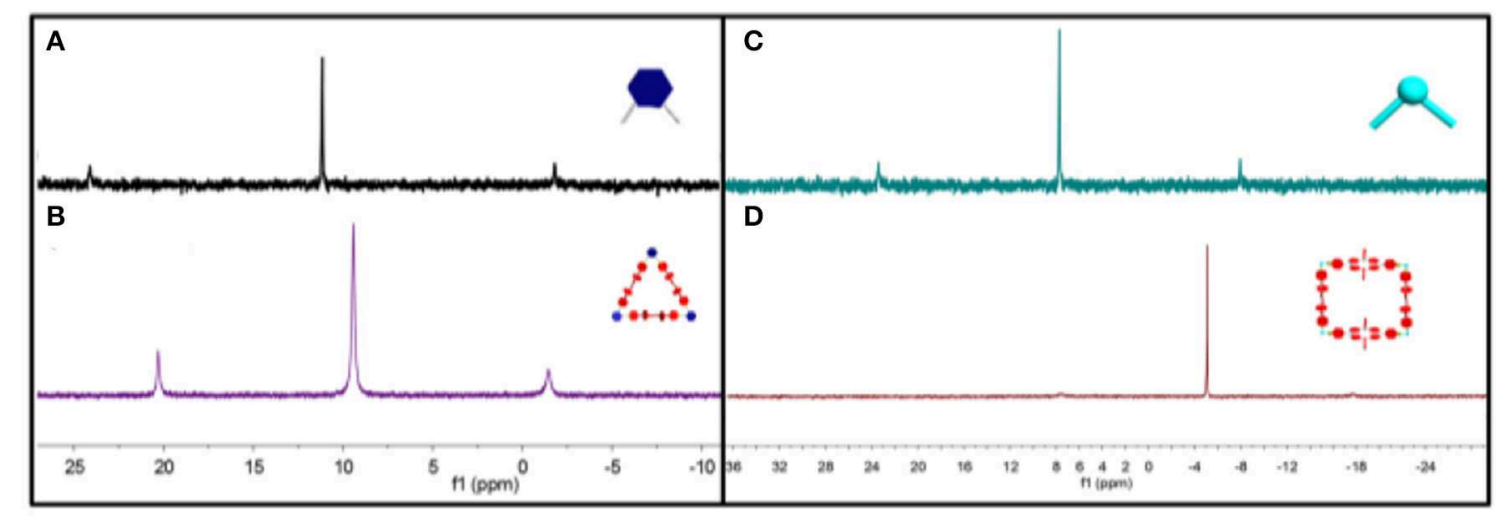

FIGURE 1 | $^{31} \mathrm{P}\left\{{ }^{1} \mathrm{H}\right\}$ NMR spectra (room temperature, $121.4 \mathrm{MHz}$ ) of (A) $60^{\circ}$ acceptor $\mathbf{2}$, (B) metallacycle $\mathbf{M C 1}$, (C) $90^{\circ}$ acceptor $\mathbf{3}$, and (D) metallacycle $\mathbf{M C 2}$ in acetone.

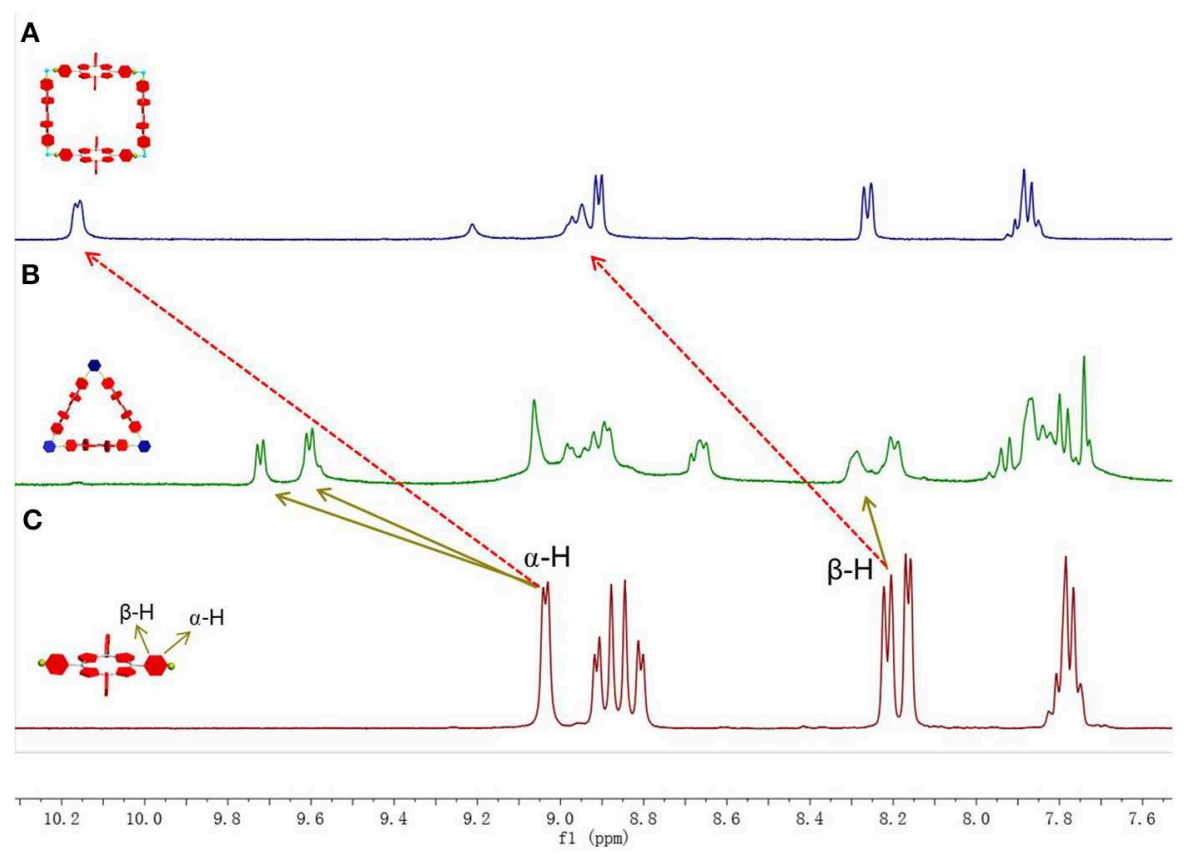

FIGURE $2 \mid{ }^{1} \mathrm{H}$ NMR spectra $\left(\mathrm{CD}_{3} \mathrm{COCD}_{3}\right.$, room temperature) of (A) bipyridylporphyrin 1, (B) metallacycle $\mathbf{M C 1}$, and (C) metallacycle $\mathbf{M C 2}$.

an intact $[\mathrm{M}-3 \mathrm{OTf}]^{3+}$ charge state, which supported a $[3+$ 3] metallacycle (Figure 3A). Similarly, for metallacycle MC2, the peak at $\mathrm{m} / \mathrm{z}=1,316.92$ is consistent with an intact $[\mathrm{M}+8$ $\left.\mathrm{CH}_{3} \mathrm{COCH}_{3}-4 \mathrm{OTf}\right]^{4+}$ charge state, which is expected only for a $[4+4]$ metallacycle (Figure 3B). All the evidence from ${ }^{1} \mathrm{H}$ NMR, ${ }^{31} \mathrm{P}$ NMR, and ESI-TOF-MS confirmed the formation of a discrete structure as the sole assembly product.

\section{Photooxidization Studies}

As we all know, porphyrins have the ability to generate ${ }^{1} \mathrm{O}_{2}$ due to the fact that they could be excited into ${ }^{3} \mathrm{O}_{2}$ state under irradiation and the energy transfer process is accompanied with molecular $\mathrm{O}_{2}$. However, due to the strong $\pi-\pi$ interactions, most porphyrins applied as photosensitizers are easily aggregated in aqueous solution (Figures S4, S5). This aggregation will greatly restrain the ability of the porphyrins to generate reactive oxygen species. For our obtained metallacycles MC1 and MC2, the coordination bonds will decrease the self-quenching of the excited states and improve the photooxidization efficiency. Therefore, metallacycles MC1 and MC2 can be used as an expected catalyst for the photoreaction mediated by ${ }^{1} \mathrm{O}_{2}$. Herein quinol was selected as a model substrate for detecting the reactivity, and UV-vis spectroscopy was used to monitor the process. As shown in Figure 4, after $20 \mathrm{ml}$ of aqueous solution of quinol $\left(10^{-2} \mathrm{mmol} \mathrm{L}^{-1}\right)$ was irradiated by a LED lamp (500 nm) under air with MC1 (5 mg) as catalyst, the absorption band 
A
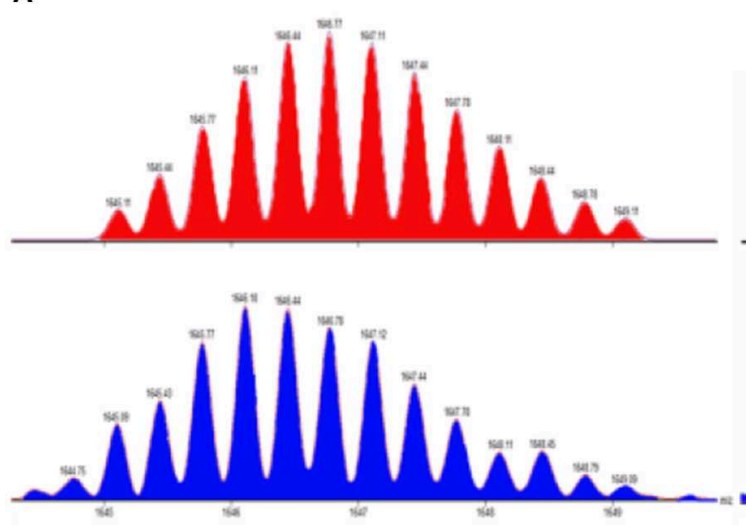

B

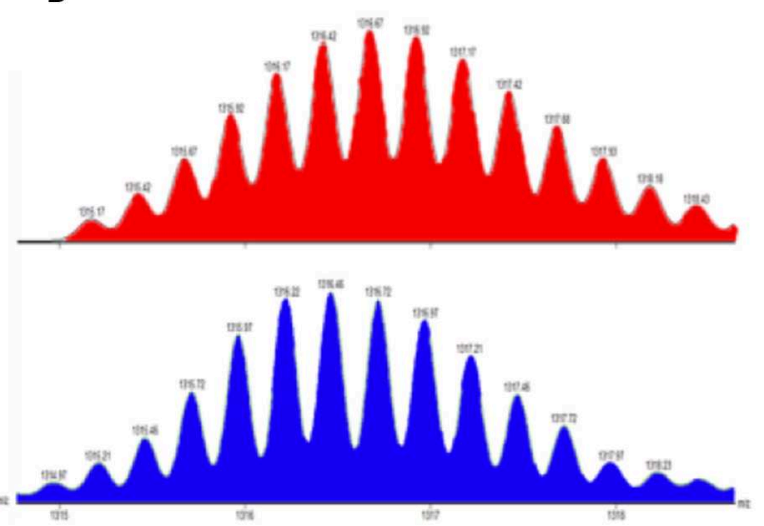

FIGURE 3 | Experimental (blue) and calculated (red) ESI-TOF-MS spectra of (A) $[\mathrm{M}-3 \mathrm{OTf}]^{3+}$ and (B) $\left[\mathrm{M}+8 \mathrm{CH}_{3} \mathrm{COCH}_{3} 4 \mathrm{OTf}\right]^{4+}$.

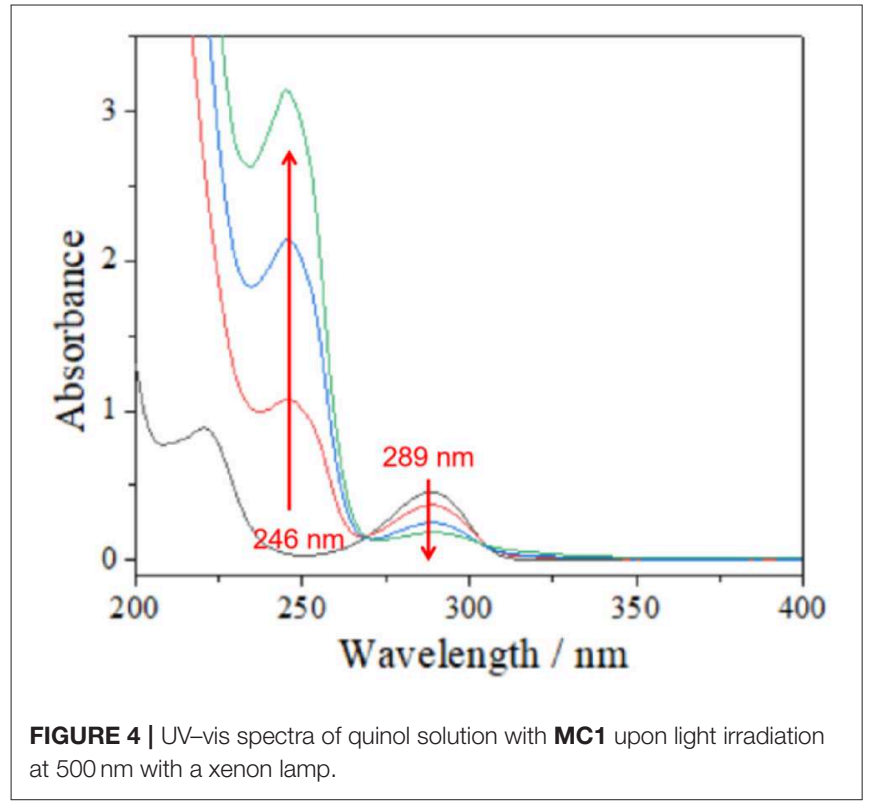

of the phenyl moiety in quinol in $289 \mathrm{~nm}$ gradually decreased, and $65 \%$ of quinol was consumed after irradiation for $60 \mathrm{~min}$ (Figure 4). As expected, MC2 has a similar catalytic efficiency with MC1 (Figure S2). However, in the control experiments using the ligand $\mathbf{1}$ as catalyst instead of $\mathbf{M C 1}$, only $8 \%$ of quinol was reacted after irradiation at 500 for $60 \mathrm{~min}$ under the same conditions (Figure S2). Importantly, the investigation for the recyclability of MC1 showed that they could be recovered by simple filtration and reused without significant loss of catalytic activity (yield loss within 5\% for six cycles, Figure S3).

\section{CONCLUSIONS}

In this paper, we synthesized two metallacycles, MC1 and MC2, with $p$-bipyridines modified porphyrin as the ligands through coordination-driven self-assembly. Then, the obtained metallacycles were characterized by ${ }^{31} \mathrm{P} \mathrm{NMR},{ }^{1} \mathrm{H} \mathrm{NMR}$, and ESI-TOF-MS methods. Furthermore, the metallacycles MC1 and MC2 can be used as an expected catalyst for the photoreaction mediated by ${ }^{1} \mathrm{O}_{2}$ due to the coordination bonds that will decrease the self-quenching of the excited states of porphyrin units and improve the photooxidization efficiency. Our next study will focus on the application of our metallacycles in photodynamic therapy.

\section{DATA AVAILABILITY STATEMENT}

All datasets generated for this study are included in the article/Supplementary Material.

\section{AUTHOR CONTRIBUTIONS}

LW, CH, and ZW prepared the ligands. LW, XW, and FS constructed the metallacycles. $\mathrm{ML}$ and $\mathrm{QZ}$ did the photooxidization. LW and XJ analyzed the data. LW, QZ, and $\mathrm{XJ}$ wrote the paper.

\section{FUNDING}

This work was supported by the National Natural Science Foundation of China (Award Nos. 21907010 and 21402012), the Natural Science Foundation of Shanxi Province (Award No. 201801D221082), the Scientific and Technological Innovation Programs of Higher Education Institutions in Shanxi (Award No. 2019L0913), and the Shanxi 1331 Project Key Innovative Research Team and the Undergraduate Innovation and Entrepreneurship Project of Shanxi Province (Award No. 2019603).

\section{SUPPLEMENTARY MATERIAL}

The Supplementary Material for this article can be found online at: https://www.frontiersin.org/articles/10.3389/fchem. 2020.00262/full\#supplementary-material 


\section{REFERENCES}

Barrow, S. J., Kasera, S., Rowland, M. J., Barrio, J., and Scherman, O. A. (2015). Cucurbituril-based molecular recognition. Chem. Rev. 115:12320. doi: 10.1021/acs.chemrev.5b00341

Cai, Y., Wang, Y., Wang, C., Long, R., Cao, L., Chen, Y., et al. (2020). Hierarchical self-assembly of 3D amphiphilic discrete organoplatinum(II) metallacage in water. Chin. Chem. Lett. 31, 689-692. doi: 10.1016/j.cclet.2019.08.036

Chen, J., Wang, Y., Wang, C., Long, R., Chen, T., and Yao, Y. (2019). Functionalization of inorganic nanomaterials with pillar[n]arenes. Chem. Commun. 55, 6817-6826. doi: 10.1039/C9CC03165K

Chen, Y., Sun, S., Lu, D., Shi, Y., and Yao, Y. (2019). Water-soluble supramolecular polymers constructed by macrocycle-based host-guest interactions. Chin. Chem. Lett. 30, 37-43. doi: 10.1016/j.cclet.2018.10.022

Dong, S., Zheng, B., Wang, F., and Huang, F. (2014). Supramolecular polymers constructed from macrocycle-based host-guest molecular recognition motifs. Acc. Chem. Res. 47, 1982-1994. doi: 10.1021/ar5000456

Gao, L., Li, M., Ehrmann, S., Tu, Z., and Haag, R. (2019). Positively charged nanoaggregates based on zwitterionic pillar[5] arene that combat planktonic bacteria and disrupt biofilms. Angew. Chem. Int. Ed. 58, 3645-3649. doi: 10.1002/anie.201810314

Gao, S., Yan, X., Xie, G., Zhu, M., Ju, X., Stang, P. J., et al. (2019). Membrane intercalation-enhanced photodynamic inactivation of bacteria by a metallacycle and TAT-decorated virus coat protein. Proc. Natl. Acad. Sci. U.S.A. 116, 23437-23443. doi: 10.1073/pnas.1911869116

Grishagin, I. V., Pollock, J. B., Kushal, S., Cook, T. R., Stang, P. J., and Olenyuk, B. Z. (2014). In vivo anticancer activity of rhomboidal Pt(II) metallacycles. Proc. Natl. Acad. Sci. U.S.A. 111, 18448-18453. doi: 10.1073/pnas.1418712111

Kim, H. J., Lee, M. H., Mutihac, L., Vicens, J., and Kim, J. S. (2012). Hostguest sensing by calixarenes on the surfaces. Chem. Soc. Rev. 41, 1173-1190. doi: 10.1039/C1CS15169J

Kim, K., Selvapalam, N., Ko, Y. H., Park, K. M., Kim, D., and Kim, J. (2007). Functionalized cucurbiturils and their applications. Chem. Soc. Rev. 36, 267-279. doi: 10.1039/B603088M

Lai, W.-F., Rogach, A. L., and Wong, W.-T. (2017). Chemistry and engineering of cyclodextrins for molecular imaging. Chem. Soc. Rev. 46, 6379-6419. doi: 10.1039/C7CS00040E

Li, P.-Y., Chen, Y., Chen, C.-H., and Liu, Y. (2019). Amphiphilic multi-charged cyclodextrins and vitamin $\mathrm{K}$ co-assembly as a synergistic coagulant. Chem. Commun. 55:11790. doi: 10.1039/C9CC06545H

Liang, X., Li, X., Yue, X., and Dai, Z. (2011). Conjugation of porphyrin to nanohybrid cerasomes for photodynamic diagnosis and therapy of cancer. Angew. Chem. Int. Ed. 50, 11622-11627. doi: 10.1002/anie.2011 03557

Liu, Z., Nalluri, S. K. M., and Stoddart, J. F. (2017). Surveying macrocyclic chemistry: from flexible crown ethers to rigid cyclophanes. Chem. Soc. Rev. 46, 2459-2478. doi: 10.1039/C7CS00185A

Nimse, S. B., and Kim, T. (2013). Biological applications of functionalized calixarenes. Chem. Soc. Rev. 42, 366-386. doi: 10.1039/C2CS3 $5233 \mathrm{H}$

Ogoshi, T., Yamagishi, T.-,a., and Nakamoto, Y. (2016). Pillar-shaped macrocyclic hosts pillar[n]arenes: new key players for supramolecular chemistry. Chem. Rev. 116, 7937-8002. doi: 10.1021/acs.chemrev.5b00765

Ou, C., Zhang, Y., Pan, D., Ding, K., Zhang, S., Xu, W., et al. (2019). Zinc Porphyrin-polydopamine core-shell nanostructures for enhanced photodynamic/photothermal cancer therapy. Mater. Chem. Front. 3, 1786-1792. doi: 10.1039/C9QM00197B

Qin, Y., Chen, L.-J., Dong, F., Jiang, S.-T., Yin, G.-Q., Li, X., et al. (2019). Light-controlled generation of singlet oxygen within a discrete dualstage metallacycle for cancer therapy. J. Am. Chem. Soc. 141, 8943-8950. doi: $10.1021 /$ jacs.9b02726

Slater, A. G., Hu, Y., Yang, L., Argent, S. P., Lewis, W., Blunt, M. O., et al. (2015). Thymine functionalised porphyrins, synthesis and heteromolecular surface-based self-assembly. Chem. Sci. 5, 1562-1569. doi: 10.1039/C4SC0 $3531 \mathrm{C}$
Sun, S., Geng, M., Huang, L., Chen, Y., Cen, M., Lu, D., et al. (2018). A new amphiphilic pillar[5]arene: synthesis and controllable self-assembly in water and application in white-light-emitting systems. Chem. Commun. 54, 13006-13009. doi: 10.1039/C8CC07658H

Wang, Y., Cai, Y., Cao, L., Cen, M., Chen, Y., Zhang, R., et al. (2019a). An amphiphilic metallaclip with enhanced fluorescence emission in water: synthesis and controllable self-assembly into multi-dimensional microstructures. Chem. Commun. 55, 10132-10134. doi: 10.1039/C9CC04809J

Wang, Y., Wang, C., Long, R., Cao, Y., Fan, D., Cen, M., et al. (2019b). Synthesis and controllable self-assembly of 3D amphiphilic organoplatinum(II) metallacages in water. Chem. Commun. 55, 5167-5170. doi: 10.1039/C9CC02173F

Wei, P., Cook, T. R., Yan, X., Huang, F., and Stang, P. J. (2014). A discrete amphiphilic organoplatinum(II) metallacycle with tunable lower critical solution temperature behavior. J. Am. Chem. Soc. 136, 15497-15500. doi: $10.1021 /$ ja5093503

Wu, J.-R., and Yang, Y.-W. (2019). New opportunities in synthetic macrocyclic arenes. Chem. Commun. 55, 1533-1543. doi: 10.1039/C8CC09374A

Xiao, T., Zhou, L., Xu, L., Zhong, W., Zhao, W., Sun, X.-Q., et al. (2019). Dynamic materials fabricated from water soluble pillar[n]arenes bearing triethylene oxide groups. Chin. Chem. Lett. 30, 271-276. doi: 10.1016/j.cclet.2018.05.039

Xue, M., Yang, Y., Chi, C., Zhang, Z., and Huang, F. (2012). Pillararenes, a new class of macrocycles for supramolecular chemistry. Acc. Chem. Res. 45, 1294-1308. doi: 10.1021/ar2003418

Yan, X., Wei, P., Liu, Y., Wang, M., Chen, C., Zhao, J., et al. (2019). Endoand exo-functionalized tetraphenylethylene M12L24 nanospheres: fluorescence emission inside a confined space. J. Am. Chem. Soc. 141, 9673-9679. doi: 10.1021/jacs.9b03885

Yao, Y., Sun, Y., Yu, H., Chen, W., Dai, H., and Shi, Y. (2017). A pillar[5]arene based gel from a low-molecular-weight gelator for sustained dye release in water. Dalton Trans. 46, 16802-16806. doi: 10.1039/C7DT04001F

Yao, Y., Zhao, R., Shi, Y., Cai, Y., Chen, J., Sun, S., et al. (2018). 2D amphiphilic organoplatinum(II) metallacycles: their syntheses, self-assembly in water and potential application in photodynamic therapy. Chem. Commun. 54, 8068-8071. doi: 10.1039/C8CC04423F

Zhang, Z., Zhao, Z., Hou, Y., Wang, H., Li, X., He, G., et al. (2019). Aqueous platinum(II) cage-based light-harvesting system for photocatalytic crosscoupling hydrogen evolution reaction. Angew. Chem. Int. Ed. 58, 8862-8866. doi: 10.1002/anie.201904407

Zhou, W.-L., Zhao, X., Chen, Y., and Liu, Y. (2019). Construction and heterogeneous photooxidization reactivity of a cyclodextrin/porphyrin polyrotaxane network. Org. Chem. Front. 6, 10-14. doi: 10.1039/C8QO00790J

Zhu, K., Vukotic, V. N., Noujeim, N., and Loeb, S. J. (2012). Bis(benzimidazolium) axles and crown ether wheels: a versatile templating pair for the formation of [2] rotaxane molecular shuttles. Chem. Sci. 3, 3265-3271. doi: $10.1039 / \mathrm{c} 2 \mathrm{sc} 20986 \mathrm{a}$

Zou, Q., Abbas, M., Zhao, L., Li, S., Shen, G., and Yan, X. (2017). Biological photothermal nanodots based on self-assembly of peptideporphyrin conjugates for antitumor therapy. J. Am. Chem. Soc. 139, 1921-1927. doi: $10.1021 /$ jacs.6b11382

Conflict of Interest: The authors declare that the research was conducted in the absence of any commercial or financial relationships that could be construed as a potential conflict of interest.

The reviewer ML declared a shared affiliation, with no collaboration, with one of the authors QZ to the handling editor at time of review.

Copyright (C) $2020 \mathrm{Wu}$, Han, Wang, Wu, Su, Li, Zhang and Jing. This is an openaccess article distributed under the terms of the Creative Commons Attribution License (CC BY). The use, distribution or reproduction in other forums is permitted, provided the original author(s) and the copyright owner(s) are credited and that the original publication in this journal is cited, in accordance with accepted academic practice. No use, distribution or reproduction is permitted which does not comply with these terms. 